\title{
Experimental investigation on a dual-mode seasonal solar thermochemical sorption energy storage system
}

\author{
T.X. Li $^{* a}$, S. Wu ${ }^{\text {a }}$, T. Yan ${ }^{\text {a }}$ R.Z. Wang ${ }^{\text {a }}$ J. Zhu', \\ ${ }^{a}$ Institute of Refrigeration and Cryogenics, Shanghai Jiao Tong University, Shanghai 200240, China \\ ${ }^{b}$ Department of Architecture and Built Environment, University of Nottingham, Nottingham NG7 2RD, UK
}

\begin{abstract}
A dual-mode seasonal solar thermochemical sorption energy storage system using working pair of expanded graphite/ $\mathrm{SrCl}_{2}-\mathrm{NH}_{3}$ was constructed and investigated. Solar thermal energy is transformed into chemical bonds in summer, and the stored energy is released in the form of chemical reaction heat in winter. Two working modes are performed to produce heat with expected temperature according to the different ambient temperatures in winter. The direct heating supply mode is adopted at a relatively high ambient temperature. The effective energy storage density is higher than $700 \mathrm{~kJ} / \mathrm{kg}$ and the corresponding system COP is 0.41 when the heat output temperature and ambient temperature are $35^{\circ} \mathrm{C}$ and $15^{\circ} \mathrm{C}$, respectively. The specific heating power increases with the decrease of heat output temperature for a given ambient temperature. The temperature-lift heating supply mode is adopted to upgrade the heat output temperature at a low ambient temperature below $0^{\circ} \mathrm{C}$. It can produce heat with a temperature above $70{ }^{\circ} \mathrm{C}$ although the ambient temperature is as low as $-15^{\circ} \mathrm{C}$. It is desirable to further improve the system performance using low mass ratio and high global conversion. Experimental results showed the advanced dual-mode thermochemical sorption energy storage technology is feasible and effective for seasonal solar thermal energy storage. Key words: solar energy; seasonal energy storage; thermochemical sorption; energy
\end{abstract}

${ }^{*}$ Corresponding author. Tel.: +86-21-34206335; fax: +86-21-34206335.

E-mail address: Litx@sjtu.edu.cn (T.X. Li). 
density.

\begin{tabular}{|c|c|c|c|}
\hline \multicolumn{4}{|c|}{ Nomenclatures } \\
\hline TES & thermal energy storage & $C_{\mathrm{p}}$ & specific thermal capacity, $\mathrm{J} / \mathrm{kgK}$ \\
\hline STES & seasonal thermal energy storage & $P$ & pressure, $\mathrm{MPa}$ \\
\hline PCM & phase change material & $\Delta t$ & interval time, $\mathrm{s}$ \\
\hline HTDU & high-temperature discharge unit & $n$ & scanning times \\
\hline LTDU & low-temperature discharge unit & $m$ & mass, $\mathrm{kg}$ \\
\hline HTR & high-temperature reactor & $\stackrel{\mathrm{g}}{m}$ & mass flow rate, $\mathrm{kg} / \mathrm{s}$ \\
\hline LTR & low-temperature reactor & $\Delta H$ & phase change enthalpy, $\mathrm{kJ} / \mathrm{kg}$ \\
\hline HTE & high-temperature evaporator & $\Delta H_{\mathrm{r}}$ & chemical reaction enthalpy, $\mathrm{kJ} / \mathrm{kg}$ \\
\hline LTE & low-temperature evaporator & Subscript & \\
\hline EG & expanded graphite & $\mathrm{h}$ & high \\
\hline SHP & specific heating power, W/kg & 1 & low \\
\hline $\mathrm{COP}$ & coefficient of performance & $\mathrm{c}$ & composite sorbent \\
\hline $\mathrm{R}$ & mass ratio & cha & charging \\
\hline $\mathrm{X}$ & global conversion & discha & discharging \\
\hline $\mathrm{CM}$ & overall thermal capacity, $\mathrm{kJ} / \mathrm{K}$ & in & inlet \\
\hline TSD & thermal storage density, $\mathrm{kJ} / \mathrm{kg}$ & out & outlet \\
\hline ETSD & effective thermal storage density, $\mathrm{kJ} / \mathrm{kg}$ & $\mathrm{s}$ & sensible heat \\
\hline Dimens & onal variables & re & reactor \\
\hline$T$ & temperature, ${ }^{\circ} \mathrm{C}$ & ev & evaporation/evaporator \\
\hline$\Delta T^{\prime}$ & heat transfer temperature difference, ${ }^{\circ} \mathrm{C}$ & $\mathrm{cn}$ & condensation/condenser \\
\hline$\Delta T$ & temperature difference, ${ }^{\circ} \mathrm{C}$ & $\mathrm{ad}$ & adsorption \\
\hline$Q$ & heat quantity, kJ & de & desorption \\
\hline
\end{tabular}




\section{Introduction}

Energy storage is a key technology to improve the energy utilization efficiency and enhance the energy security for various renewable energy systems. The most research work has focused on the electric battery for energy storage of electrochemical systems. However, more than $90 \%$ of the world's primary energy generation is consumed or wasted in the form of thermal energy. Thermal energy storage (TES) plays a broad and critical role in making energy utilization more sustainable for space heating and cooling, solar energy harvesting, solar thermal power generation, and other applications [1].

Solar energy is always suffering from the problem of instability and intermittence due to the variation of solar insolation according to the weather conditions, location, time and seasons of a year. TES is considered as a paramount technology to adjust the instability and time-discrepancy between energy supply and energy demand. Therefore, reasonable utilization of solar energy inseparably depends on the development of sustainable and economically feasible TES systems. Under this circumstance, an increasing attention has been drawn to seek the possible and suitable solutions to promote TES technology in recent years [2]. Solar thermal energy storage can be divided into short-term storage and long-term/seasonal storage depending on the storage duration. The objective of the former is to store solar heat in sunny days and use it during cloudy days and/or at night, while the latter is to use excess heat collected in the summer to compensate for the heat supply insufficiency during wintertime. Nowadays, the short-term solar heat storage products such as hot water storage tanks and PCMs are available on the market [3]. Xu et al. [4] summarized the latest studies and related projects available for seasonal/long-term storage of thermal energy, including storage materials, existing plants or projects and future outlook. In comparison with the short-term thermal energy storage, long-term seasonal thermal 
energy storage (STES) is faced with more challenges, which requires larger heat storage capacity and stricter measures to prevent heat losses in the long storage period. In addition, the storage material must be economical, reliable and environmentally friendly.

Long-term solar heat storage can be realized by three methods including sensible heat storage, latent heat storage and thermochemical sorption heat storage. Sensible heat storage is a relatively mature technology that has been implemented and evaluated in many large-scale demonstration plants due to its low-cost and reliability. The storage materials are generally water [5], rock-sort material [6] and ground/soil [7]. However, this method has obvious drawbacks of low energy storage density and unsteady heat output temperature. Moreover, the heat output temperature in the discharging process is often at a low level due to the inevitable heat losses during long-term storage.

Latent heat storage using PCM can realize nearly isothermal heat output and the thermal storage density is higher than the sensible heat storage [8]. However, latent heat storage is seldom used for seasonal storage of solar thermal energy. On the one hand, large heat losses would occur unavoidably during the long-term storage. On the other hand, there exists the risk that the discharging process of PCM would happen ahead of time uncontrollably before needed in winter once its temperature is lower than the phase change temperature due to its large heat loss. Moreover, the PCM generally suffers supercooling and corrosion problem, which would severely affect the phase change process [9]. Recently, Dannemand et al. [10] utilized stable supercooling of sodium acetate trihydrate and maked it possible to store thermal energy partly loss free in the long-term energy storage process, but the PCM still suffered the deficiency of low energy density. Thus, it is inappropriate for the long-term solar heat storage in most cases. 
Thermochemical sorption energy storage has the advantages of higher energy storage density, stable heat output temperature, combined heat and cold storage, integrated energy storage and energy upgrade [11-12]. Besides these advantages, the most remarkable merit is that the thermal energy can be transformed and stored in the form of chemical bonds, which rarely depends on the value of temperature. Thus, the stored thermal energy would nearly not decrease during long-term storage period (ignoring the sensible heat of material itself). Solid-gas thermochemical sorption energy storage method has been paid much attention in recent years, especially for long-term solar thermal energy storage [13]. For this energy storage method, sorption material and gas are chosen as a sorption working pair. Hydrates and ammoniates (such as $\mathrm{MgSO}_{4} \cdot 7 \mathrm{H}_{2} \mathrm{O}$, $\mathrm{MgCl}_{2} \cdot 6 \mathrm{H}_{2} \mathrm{O}, \mathrm{CaCl}_{2} \cdot 6 \mathrm{H}_{2} \mathrm{O}, \mathrm{BaCl}_{2} \cdot 8 \mathrm{NH}_{3}, \mathrm{MnCl}_{2} \cdot 6 \mathrm{NH}_{3}$, etc.) can be employed in sorption processes for seasonal thermal energy storage [14]. Moreover, in order to improve the capacity of heat and mass transfer of sorbent, some composite sorbents made up of salts and porous materials are developed, such as zeolite/ $\mathrm{CaCl}_{2}$ [15], silica gel/salt [16], expanded graphite (EG)/salt [17], form-stable composite zeolite/MgSO 4 [18], etc. The related research results show that composite sorbent is a promising material for long-term solar thermal energy storage. Currently, studies on thermochemical sorption energy storage are still in the theoretical and laboratory testing stage, mostly on fundamental materials, modelling and system optimization.

Mauran et al. [19] constructed and tested a thermochemical sorption energy storage system using $\mathrm{SrBr}_{2}-\mathrm{H}_{2} \mathrm{O}$ sorption working pair, and it was used to fulfill a heating and cooling storage function based on monovariant solid/gas reaction. The prototype allowed heat storage of $60 \mathrm{kWh} / \mathrm{m}^{3}$ at $70-80^{\circ} \mathrm{C}$ with a minimum of heat loss over indefinite duration and heat release of $60 \mathrm{kWh} / \mathrm{m}^{3}$ at $35^{\circ} \mathrm{C}$ within the floor heating system of a house in mid-season. Obviously, such a low heat output temperature has 
limited its potential application. Due to the monovariant characteristic of solid-gas chemical reaction, the lower ambient temperature in winter would cause a lower heat output temperature. Moreover, the prototype would be unavailable due to the fact that the water would be frozen if the ambient temperature is below $0^{\circ} \mathrm{C}$. Michel et al. [20] estimated and optimized the performance of a seasonal solid-gas thermochemical sorption process. Experimental results showed that the energy storage density of salt beds could reach about $430-460 \mathrm{kWh} / \mathrm{m}^{3}$, and the specific power between 1.93 and $2.88 \mathrm{~W} / \mathrm{kg}$. However, this optimized solid-gas thermochemical sorption energy storage process also suffered from the same drawbacks of low heat production temperature and water freezing in winter. In addition, it was difficult to improve the specific power due to the low mass transfer capacity caused by the low operation pressure.

Compared with the thermochemical sorption energy storage system based on hydrates, the system using ammoniate has advantages of high operation pressure and low freezing point of liquid ammonia. Pons et al. [21] compared different sorption systems (liquid absorption, adsorption, ammonia salts and metal hydrides) and found that thermochemical sorption systems based on ammoniate are very fit for applications of deep-freezing and heat pump. It seems that the ammoniate system is especially suitable for seasonal thermal energy storage. Recently, solid-gas thermochemical sorption thermal battery was developed for solar cooling \& heating energy storage and heat transformer [22], and it could be used for the short-term and long-term storage of solar thermal energy and integrated energy storage and energy upgrade. Experimental verification showed that sorption thermal battery can achieve combined deep-freezing cold and heat energy storage, and its working temperature can be easily adjusted by changing system pressure. The cold and heat energy densities are as high as $600 \mathrm{~kJ} / \mathrm{kg}$ and $1498 \mathrm{~kJ} / \mathrm{kg}$, respectively using consolidated composite sorbent of expanded 
graphite/manganese chloride-ammonia [23]. Moreover, sorption thermal battery can achieve cascaded thermal energy storage to enhance the versatility and working reliability of solar heat storage system by using solid-gas thermochemical multilevel sorption processes with several reactive salts [24]. In order to improve the usability of seasonal thermochemical sorption energy storage, Li et al. [25] proposed a novel dualmode solid-gas thermochemical sorption energy storage system based on metal chloride and ammonia for seasonal solar thermal storage. The system is comprised of a lowtemperature unit and a high-temperature unit, and it has two discharging modes according to different ambient temperatures in winter. When the ambient temperature is relatively high, the both heat released by two units are directly used to supply the heat for user. When the ambient temperature is low and it would cause low heat output temperature which is unable to meet user's demand, a heat transformer cycle is performed to achieve a high heat output temperature using temperature-lift heating supply mode in which the heat released by low-temperature unit is used to supply the evaporation heat and elevate the working pressure of high-temperature unit. The theoretical analysis showed that the proposed method was effective for the long-term seasonal storage of solar energy. The COP and energy density of the system could reach 0.6 and $1000 \mathrm{~kJ} / \mathrm{kg}$ salt. Currently, there is a lack of related experiment research on the novel temperature-lift heating supply mode using internal heat recovery method in solid-gas thermochemical sorption energy storage.

The aim of this work is to investigate the feasibility and working performance of the novel dual-mode seasonal thermochemical sorption energy storage based on the previous theoretical research. A corresponding experiment testing system is constructed using EG/strontium chloride-ammonia working pair. The thermal storage densities and working performance of two working modes of the proposed system are investigated 
experimentally and analyzed according to different ambient temperatures in winter during the discharging phase. Moreover, some potential performance improvement measures are proposed depending on experiment testing results.

\section{Working principle and experimental system of STES cycle}

The working principle of advanced dual-mode seasonal solid-gas thermochemical sorption energy storage system was introduced in detail in the previous theoretical research [25]. The system consists of two energy storage units, and every unit mainly contains one solid-gas reactor and one refrigerant vessel. The working process of the system is divided into two phases: charging phase (also known as desorption or decomposition), and discharging phase (also referred to as adsorption or synthesis). The refrigerant vessel acts as condenser during the charging phase and as evaporator during the discharging phase. The charging phase is conducted in summer, in which solar thermal energy is transformed and stored in the form of chemical bonds due to the thermochemical desorption processes.

The discharging phase occurs in winter, when the ambient temperature is low and the stored thermal energy needs to be released. In this phase, evaporators are connected to the reactors and the chemical synthesis reaction processes take place in order to realize the transformation from chemical bonds energy into thermal energy. Two working modes could be interchanged to produce the thermal energy with a desirable heat output temperature according to different ambient temperatures in winter, which are named as direct heating supply mode and temperature-lift heating supply mode. The direct heating supply mode is performed when the ambient temperature in winter is relatively high. In this working mode, two energy storage units operate independently and produce heat with a relatively high temperature to meet the heat requirement. 
However, when the ambient temperature is relatively low, the chemical synthesis heat released by the two units would also have low output temperature due to the monovariant characteristic of chemical reaction between metal chloride and ammonia, which would not satisfy the heat requirement. In this case, the temperature-lift heating supply mode with an internal heat recovery process is employed to elevate heat output temperature by combining two discharge units. Fig. 1 shows the schematic diagram of the temperature-lift heating supply mode of dual-mode solid-gas thermochemical sorption energy storage system. The two units are named as high-temperature discharge unit (HTDU) and low-temperature discharge unit (LTDU), respectively. For convenience, the reactors and evaporators in the HTDU and LTDU are referred to as high-temperature reactor (HTR), low-temperature reactor (LTR), high-temperature evaporator (HTE) and low-temperature evaporator (LTE). The reaction heat produced by the LTR during the discharging phase is used to heat the HTE in order to elevate the working pressure from $P_{\text {l-ev }}$ to $P_{\mathrm{h}-\mathrm{ev}}$ in the HTDU. As a result, the heat output temperature increases from $\mathrm{T}_{\mathrm{LTR}}$ to $\mathrm{T}_{\mathrm{HTR}}$ to meet the heat requirement. Hence, the temperature-lift heating supply mode could produce heat with an appropriate temperature without the restriction of ambient temperature in winter.

The suitable sorption working pair is firstly selected to verify the feasibility of the advanced dual-mode seasonal solid-gas thermochemical sorption energy storage system. The driving heat temperature of sorption working pair should be below $100{ }^{\circ} \mathrm{C}$ in order to effectively utilize solar thermal energy using conventional economical solar collector. The common promising sorption working pairs are shown in Table 1. The sorption working pair of strontium chloride-ammonia is chosen as suitable sorption working pair due to its favorable operation temperature and promising behavior during decomposition-synthesis cycle. 
A seasonal solid-gas thermochemical sorption energy storage system using EG/strontium chloride-ammonia working pair was designed and constructed to achieve the dual-mode heating supply. Fig.2 shows the photograph of experimental prototype for seasonal solid-gas thermochemical sorption energy storage, which mainly includes the reactor, pressure sensors, ammonia valve, condenser/evaporator, data logger, hightemperature thermostatic bath and low-temperature thermostatic bath. Two shell-andtube type heat exchangers are used to fabricate solid-gas reactor. Ten finned tubes are encapsulated in every shell-and-tube type heat exchanger. $3.72 \mathrm{~kg} \mathrm{SrCl}_{2}$ are impregnated into EG matrix following the procedure given by Oliveira et al. [27] according to the mass ratio of $85: 15$ to produce composite sorbent, which are filled into the gaps of finned pipes. The EG could enhance the heat and mass transfer properties of the composite sorbent due to its high porosity and high thermal conductivity.

The experimental prototype was placed in a high-temperature and low-temperature thermostatic chamber. The operating temperature of thermostatic chamber can be changed in order to simulate the different ambient temperatures in summer and winter for the long-term seasonal energy storage. The heat input temperatures of reactor and condenser/evaporator are adjusted by changing the temperatures of heat transfer fluid from the high-temperature and low-temperature thermostatic baths. Two pressure sensors (full scale from 0 to $4.0 \mathrm{MPa}$ with tolerance of $\pm 0.5 \%$ ) are installed in the reactor and condenser/evaporator to measure the working pressures inside them. Several Pt100 thermal resistance temperature sensors (full scale from -50 to $450^{\circ} \mathrm{C}$ with accuracy of $\pm 0.5 \%$ ) are used to measure inlet temperatures and outlet temperatures of the reactor and condenser/evaporator ( $\left.T_{\mathrm{in}, \mathrm{e}}, T_{\text {out,re }}, T_{\mathrm{in}, \mathrm{cn}}, T_{\text {out,cn }}, T_{\mathrm{in}, \mathrm{ev}} T_{\text {out,ev }}\right)$ and the temperature inside the reactor $\left(T_{\mathrm{re}}\right)$. The experimental data are monitored and recorded by an Agilient 34927A data logger. The quantity of liquid ammonia in the condenser/ 
evaporator can be observed by the float level meter.

The high-temperature thermostatic bath is used to simulate the external heat source from solar thermal energy in summer. In order to investigate the comprehensive performance of the seasonal thermochemical sorption thermal energy storage system, the charging phase keeps a long time to regenerate the composite sorbent as completely as possible. The heat input temperature of reactor (also the external heat source temperature) and the condensation temperature (also ambient temperature) are set at about $94^{\circ} \mathrm{C}$ and $25^{\circ} \mathrm{C}$, respectively. For the discharging phase, preliminary experimental results showed that heat output temperature of reactor could reach $55^{\circ} \mathrm{C}$ when the ambient temperature is $0^{\circ} \mathrm{C}$, which could meet the most situations of residential heat requirement, such as hot water supply and low-temperature radiant floor heating system. Therefore, the direct heating supply mode of seasonal solar thermal energy storage is firstly performed as ambient temperature varies between 0 and $15^{\circ} \mathrm{C}$. Then, the temperature-lift heating supply mode of seasonal solar thermal energy storage is tested and analyzed when the ambient temperature is below $0^{\circ} \mathrm{C}$.

\section{Performance evaluation}

The total heat consumption of seasonal thermochemical sorption energy storage system during the charging phase can be calculated by:

$$
Q_{\text {cha }}=\sum_{i=0}^{n} \stackrel{g}{m} C_{\mathrm{p}}\left(T_{\text {in,re }}-T_{\text {out, re }}\right)_{\mathrm{i}} \Delta t
$$

where $Q_{\text {cha }}$ contains the chemical decomposition heat, the sensible heat consumed by the composite sorbent and metal of reactor with temperature increasing from ambient temperature $\left(T_{\mathrm{a}}\right)$ to the constant temperature, and the heat dissipation of reactor. Depending on the energy conservation law, it equals to the energy variation of heat 
exchange fluid as shown in the right hand side of Equation (1). $\Delta t$ is time interval between every two scanning data. $n$ is the scanning times. $\stackrel{\mathrm{g}}{m}$ and $C_{\mathrm{p}}$ are the mass flow rate and mass specific thermal capacity of heat transfer fluid, respectively. $T_{\text {in,re }}$ and $T_{\text {out,re }}$ are the inlet and outlet temperature of reactor.

The total heat production of seasonal thermochemical sorption energy storage system during the discharging phase can be calculated by:

$$
\begin{gathered}
Q_{\text {discha }}=\sum_{i=0}^{n} \stackrel{\mathrm{g}}{m} C_{\mathrm{p}}\left(T_{\text {out,re }}-T_{\text {in,re }}\right)_{\mathrm{i}} \Delta t \\
Q_{\text {output }}=Q_{\text {discha }}-Q_{\mathrm{s}} \\
Q_{\mathrm{s}}=C M\left(T_{\text {out }}-T_{\mathrm{a}}\right)
\end{gathered}
$$

where $Q_{\text {discha }}$ is the total heat production during the discharging phase, $Q_{\text {ouput }}$ is the useful heat production for end user. $Q$ is the sensible heat consumption of reactor with temperature increasing from ambient temperature $\left(T_{\mathrm{a}}\right)$ to output temperature $\left(T_{\text {out }}\right)$. CM is the overall thermal capacity of reactor, which contains thermal capacity of all metal material, composite sorbent and even heat dissipation. $\mathrm{CM}$ can be obtained experimentally.

The mass thermal storage density $\left(\mathrm{TSD}_{\mathrm{m}}\right)$ and the effective mass thermal storage density $\left(\mathrm{ETSD}_{\mathrm{m}}\right)$ :

$$
\begin{aligned}
& \operatorname{TSD}_{\mathrm{m}}=Q_{\text {discha }} / m_{\mathrm{c}} \\
& \operatorname{ETSD}_{\mathrm{m}}=Q_{\text {output }} / m_{\mathrm{c}}
\end{aligned}
$$

where $m_{\mathrm{c}}$ is the mass of the composite sorbent.

Thermal storage efficiency (COP) and the specific heating power (SHP):

$$
\begin{gathered}
\mathrm{COP}=Q_{\text {output }} / Q_{\text {cha }} \\
\mathrm{SHP}=Q_{\text {discha }} /\left(m_{\mathrm{c}} t\right)
\end{gathered}
$$


where $t$ is the time the discharging process goes.

The mass ratio $(R)$ is defined as the ratio of metal mass (including metal shell, finned tubes) divided by the mass of composite sorbent in the reactor. The global conversion $(X)$ is defined as the ratio of the reactive salt reacted with ammonia divided by the total salt in the reactor. They can be expressed as:

$$
\begin{aligned}
R & =m_{\text {metal }} / m_{\mathrm{c}} \\
X & =m_{\text {reactive salt }} / m_{\text {total salt }}
\end{aligned}
$$

The thermal storage density, COP and SHP are three major parameters involved in the performance evaluation of thermochemical sorption system, and their relative tolerances are calculated as follows:

$$
\begin{gathered}
\left|\frac{\mathrm{dTSD}}{\mathrm{TSD}}\right| \leq\left|\frac{\mathrm{d} m_{\mathrm{c}}}{m_{\mathrm{c}}}\right|+\left|\frac{\mathrm{d} Q_{\text {discha }}}{Q_{\text {discha }}}\right|=\left|\frac{\mathrm{d} m_{\mathrm{c}}}{m_{\mathrm{c}}}\right|+\left|\frac{\mathrm{d} m}{\mathrm{~g}}\right|+\left|\frac{\mathrm{d} \Delta T}{\Delta T}\right| \\
\left|\frac{\mathrm{dCOP}}{\operatorname{COP}}\right| \leq\left|\frac{\mathrm{d} Q_{\text {output }}}{Q_{\text {output }}}\right|+\left|\frac{\mathrm{d} Q_{\text {cha }}}{Q_{\text {cha }}}\right|=\left|\frac{\mathrm{d} Q_{\text {discha }}}{Q_{\text {discha }}}\right|+\left|\frac{\mathrm{d} Q_{\mathrm{s}}}{Q_{\mathrm{s}}}\right|+2\left|\frac{\mathrm{d} Q_{\text {cha }}}{Q_{\text {cha }}}\right|=3\left|\frac{\mathrm{d} \frac{\mathrm{g}}{m}}{\frac{\mathrm{g}}{m}}\right|+4\left|\frac{\mathrm{d} \Delta T}{\Delta T}\right|+\left|\frac{\mathrm{d} C M}{C M}\right| \\
\left|\frac{\mathrm{dSHP}}{\mathrm{SHP}}\right| \leq\left|\frac{\mathrm{d} m_{\mathrm{c}}}{m_{\mathrm{c}}}\right|+\left|\frac{\mathrm{d} Q_{\text {discha }}}{Q_{\text {discha }}}\right|=\left|\frac{\mathrm{d} m_{\mathrm{c}}}{m_{\mathrm{c}}}\right|+\left|\frac{\mathrm{d} \frac{\mathrm{g}}{m}}{\frac{\mathrm{g}}{m}}\right|+\left|\frac{\mathrm{d} \Delta T}{\Delta T}\right|
\end{gathered}
$$

The maximum relative tolerances of them are $2.0 \%, 6.8 \%$ and $2.0 \%$, respectively.

\section{Results and discussion}

Two heating supply modes were investigated and analyzed successively according to the different ambient temperatures in winter. Fig. 3 shows the working temperature range of corresponding components of two working modes during the discharging phase based on preliminary experiment results. When the ambient temperature is above $0^{\circ} \mathrm{C}$, the direct heating supply mode is adopted to produce thermal energy with a heat output temperature above $55^{\circ} \mathrm{C}$. When the ambient temperature is below $0^{\circ} \mathrm{C}$, the 
temperature-lift heating supply mode is employed to elevate the heat output temperature. The temperature-lift heating supply mode can not only widen the application of seasonal solar thermal energy storage at the lower ambient temperature, but also broaden the heat output temperature range to a large extent.

\subsection{Direct heating supply mode of seasonal solar thermal energy storage}

\subsubsection{Temperature evolution curves}

One representative working condition is selected to illustrate the operation process of seasonal solar thermochemical sorption energy storage system. Fig.4 shows temperature evolution curves under the condition of heat source temperature of $94^{\circ} \mathrm{C}$ in summer and ambient temperature of $10^{\circ} \mathrm{C}$ in winter. First, the reactor and condenser are both at ambient temperature of $25^{\circ} \mathrm{C}$ in summer, and then the heat transfer fluid with a temperature of $94{ }^{\circ} \mathrm{C}$ from the external heat source (which can be supplied by solar collector) is pumped to heat reactor. It is observed that the outlet temperature of condenser begins to increase obviously when the temperature inside reactor reaches about $78^{\circ} \mathrm{C}$. It indicates that the ammonia is gradually desorbed from the composite sorbent, and the gaseous ammonia starts to condense. The decomposition-condensation process takes around 150 minutes to regenerate the $\mathrm{SrCl}_{2}$ enough. Then, the ammonia valve is closed to separate the reactor and condenser. Thermal energy is transformed and stored in the form of chemical bonds of sorption working pair during the charging phase.

At the beginning stage during the discharging phase, it is assumed that the reactor and condenser are cooled down to the ambient temperature of $10{ }^{\circ} \mathrm{C}$ in winter after seasonal storage period due to the inevitable heat losses between energy storage unit and external environment. Once the stored thermal energy is needed to release in order 
to meet the heat demand of end user, the ammonia valve is opened and the synthesisevaporation process occurs. The temperature inside reactor increases from 10 to $65^{\circ} \mathrm{C}$ promptly under the heat treatment by consuming a little part of chemical synthesis heat released by the chemical reaction between $\mathrm{SrCl}_{2}$ and ammonia. Actually, the peak temperature of reactor represents the maximum temperature that the heat transfer fluid can reach in the course of chemical synthesis reaction, however, the highest heat output temperature is generally $2-3^{\circ} \mathrm{C}$ lower than the corresponding peak temperature. For the whole process (including charging and discharging phase), the highest system pressure is about $0.95 \mathrm{MPa}$ when the temperature inside reactor becomes constant during the charging phase.

Fig.5 shows temperature evolution curves under stable operating condition with the output temperature of $45^{\circ} \mathrm{C}$ and ambient temperature of $10^{\circ} \mathrm{C}$ during the discharging phase in winter. The evaporation heat of liquid ammonia in the evaporator is supplied by the external heat sink at an ambient temperature of $10^{\circ} \mathrm{C}$, and the outlet temperature of evaporator is always lower than its inlet temperature due to the evaporation heat consumption. At the same time, the stored thermal energy in the energy storage unit is released in the form of the chemical synthesis heat of reactor, and the chemical heat produced by the energy storage unit is used to supply heat for end user at a heat output temperature higher than $45^{\circ} \mathrm{C}$. It can be seen that the outlet temperatures of reactor are always higher than its inlet temperatures due to the chemical synthesis heat, and the temperature difference between inlet and outlet temperatures of reactor is as high as 10 ${ }^{\circ} \mathrm{C}$ during the discharging phase.

\subsubsection{Overall thermal capacity of reactor}

In order to evaluate the thermal storage density and COP of the seasonal solar 
thermal energy storage system, the overall thermal capacity (CM) of reactor as an important parameter is employed to calculate the unavoidable sensible heat consumption of reactor in the discharging phase.

For the seasonal solar thermochemical sorption energy storage system, a little part of chemical synthesis heat has to be wasted to provide the sensible heat of reactor with its temperature increasing from the ambient temperature to heat output temperature. In order to calculate the sensible heat consumption, the $\mathrm{CM}$ of reactor is firstly tested and obtained experimentally. Combining the equation (1) or (2) with (4), the CM can be calculated according to the amount of heat consumption and the corresponding temperature difference of reactor under the condition no chemical synthesis heat released in which the ammonia valve is closed. A series of temperature differences are tested in order to obtain a mean CM value. Fig. 6 shows that the variation of sensible heat consumption of reactor with its temperature difference. The slope of the fitting line stands for the mean $\mathrm{CM}$. The mean $\mathrm{CM}$ of reactor in the energy storage unit is $42.24 \mathrm{~kJ} / \mathrm{K}$, which contains the thermal capacity of composite sorbent, all metal material, enclosure material, and even the heat dissipation of reactor.

In addition, a low ambient temperature means a low evaporation temperature of evaporator in energy storage unit, and this will lead to a low heat output temperature of reactor because of the monovariant characteristic of chemical reaction between $\mathrm{SrCl}_{2}$ and $\mathrm{NH}_{3}$. Due to the sensible heat consumption of reactor, the equilibrium temperature of reactive salt corresponding to an evaporation temperature are not always reached. In order to ensure the desirable heat output temperature, the peak temperatures of reactor at different ambient temperatures in winter are tested and compared. When the ambient temperatures are $0,5,10$ and $15^{\circ} \mathrm{C}$, the corresponding peak temperatures of reactor are 58.0, 62.5, 65.0 and $69.0^{\circ} \mathrm{C}$, respectively. 


\subsubsection{Thermal storage density and system COP}

Thermal storage density of seasonal solar thermal energy storage system is calculated based on the amount of heat production and the mass of composite sorbent. Two analysis approaches are used to evaluate the amount of heat production during the discharging phase. The first one is the maximum amount of heat production by considering only the chemical synthesis reaction heat released by reactor at a certain heat output temperature using equation (2), and the other one is the amount of effective heat production by considering both chemical synthesis reaction heat released and sensible heat consumed by reactor using equation (3).

Fig.7 (a) shows the variation of mass thermal storage density at different heat output temperatures $\left(T_{\text {out }}\right)$ and ambient temperatures $\left(T_{\mathrm{a}}\right)$ without regard to the sensible heat consumption, which reflects the maximum value of chemical synthesis reaction heat. The highest thermal storage density is about $900 \mathrm{~kJ} / \mathrm{kg}$ composite sorbent when the $T_{\text {out }}$ and $T_{\mathrm{a}}$ are $35^{\circ} \mathrm{C}$ and $15^{\circ} \mathrm{C}$, respectively. For a given ambient temperature of $T_{\mathrm{a}}$, mass thermal storage density decreases with the increment of $T_{\text {out. }}$ Whereas, it would increase with the increment of $T_{\mathrm{a}}$ at a given heat output temperature of $T_{\text {out }}$. The reason could be classified into two aspects. On the one hand, the higher $T_{\text {out }}$ would cause more amount of heat dissipation during the discharging phase, which must decrease the amount of heat production. On the other hand, it could be explained from the perspective of the chemical reaction driven potential. For the same $T_{\text {out }}$, a higher $T_{\mathrm{a}}$ contributes to a higher evaporation pressure, so the initial pressure difference between reactor and evaporator is bigger, and more amount of ammonia can be adsorbed by the sorbent at the beginning stage, which means the shorter discharging time and less heat loss. Moreover, it is found that thermal storage density will decrease rapidly when the $T_{\text {out }}$ approaches to the peak 
temperature of reactor at the corresponding $T_{\mathrm{a}}$ due to the low chemical reaction driven potential.

Fig.7 (b) shows the variation of the effective mass thermal storage density based on the amount of practical heat output with the $T_{\text {out }}$ and $T_{\mathrm{a}}$, which has the same tendency with the Fig.7 (a). However, the thermal storage density decreases remarkably due to the additional sensible heat consumption of reactor. The highest thermal storage density is about $706 \mathrm{~kJ} / \mathrm{kg}$ when the $T_{\text {out }}$ and $T_{\mathrm{a}}$ are $35^{\circ} \mathrm{C}$ and $15^{\circ} \mathrm{C}$, respectively. In this case, the effective mass thermal storage density is not only influenced by the chemical reaction driven potential, but also the amount of sensible heat consumed by reactor which is determined by the temperature difference between the $T_{\mathrm{a}}$ and $T_{\text {out }}$. At different ambient temperatures of $T_{\mathrm{a}}$, the effective thermal storage density decreases with increasing the heat output temperature of $T_{\text {out }}$. Especially, there is not nearly heat output under the $T_{\mathrm{a}}$ $=0^{\circ} \mathrm{C}$ and $T_{\text {out }}=55^{\circ} \mathrm{C}$, which indicates that the chemical reaction heat is almost equal to the sensible heat consumed by reactor. Fig.7 (c) shows the system COP at different heat output temperatures and ambient temperatures. The highest COP is 0.41 when the $T_{\text {out }}$ and $T_{\mathrm{a}}$ are $35^{\circ} \mathrm{C}$ and $15^{\circ} \mathrm{C}$, respectively. The system COP is proportional to the amount of effective heat output during the discharging phase in winter due to the same amount of heat input during the charging phase in summer.

\subsubsection{Specific heating power (SHP)}

Specific heating power (SHP) is used to evaluate the heat release rate of the seasonal solar thermal energy storage system. Obviously, the SHP reflects the value of chemical reaction potential. Fig. 8 shows the evolution curves of SHP at different heat output temperatures, which indicates that the SHP firstly increases and then decreases during the discharging phase. The lower the heat output temperature is, the higher the peak 
value of SHP is. For the heat output temperatures of $35,40,45,50$ and $55^{\circ} \mathrm{C}$, the corresponding peak values of SHP are about 643, 548, 490, 358 and 254W/kg composite sorbent, respectively.

\subsubsection{Potential improved performance}

It is known that the sensible heat of reactor could be recycled to produce useful heat for the short-term thermal energy storage system during the discharging phase. However, the sensible heat of reactor has a negative contribution to the amount of effective heat output because it consumes the chemical synthesis heat at the beginning stage of discharging phase for the seasonal thermal energy storage system as mentioned above. A parameter of the mass ratio $(R)$ between metal of reactor and composite sorbent is used to evaluate the influence of sensible heat consumption on the system COP. The metal includes vessels, tubes, and fins in the reactor. In addition, the global conversion $(X)$ representing the percentage of the salt that reacts with the refrigerant during a reaction process has also a prominent influence on the system COP. Another factor which affects the COP by influencing the sensible heat consumption of reactor is the temperature difference between the $T_{\mathrm{a}}$ and $T_{\text {out }}$.

Fig.9 shows the variation of theoretical COP with $R$ at the different global conversions and temperature differences. The system COP always decreases with the increment of $\mathrm{R}$ for a given global conversion and temperature difference. For a designed experiment system with constant $R$, the high global conversion and low temperature difference contribute to a high COP. In this seasonal solar thermal energy storage system, the mass ratio is about 10.27 , and the corresponding theoretical COP is 0.70 with $X=1$ and $\Delta T=40^{\circ} \mathrm{C}$, while the experimental value of COP is just 0.22 . This is because the global conversion $X$ is lower than 1 and the heat dissipation of reactor in 
the charging and discharging phase could be not neglected in a real experiment system.

Two possible approaches can be considered to achieve the better system performance by decreasing the mass ratio $R$ or increasing the global conversion $X$. The mass ratio $R$ varying from 3 to 5 is considered to be a realizable range. The COP would increase by $54 \%$ and $26 \%$ when the $R$ decreases from 10.27 to 3 at $X=0.5$ and $X=1$, respectively. Otherwise, it is also rather significant to improve the global conversion as much as possible, which requires a considerably long reaction time or high heat and mass transfer performance of composite sorbent.

\subsection{Temperature-lift heating supply mode of seasonal solar thermal energy storage}

\subsubsection{Temperature evolution curves}

The heat output temperature of reactor would become low during the discharging phase when the ambient temperature is very low in winter, which could not meet the heat requirement of end user. In order to extend the application range of the proposed seasonal solar thermal energy storage system, the temperature-lift heating supply mode of seasonal solar thermochemical sorption energy storage system is employed to elevate the heat output temperature. In this experiment, the single thermal energy storage system is used to verify the feasibility of the temperature-lift heating supply mode of seasonal thermal energy storage system.

Fig.10 shows the discharging process of temperature-lift heating supply mode of seasonal thermochemical sorption energy storage system using the temperature match between the HTDU and LTDU. At an ambient temperature of $-15^{\circ} \mathrm{C}$ in winter, the lowtemperature evaporator (LTE) in LTDU works at ambient temperature in which the inlet temperature of heat transfer fluid is set at $-15^{\circ} \mathrm{C}$, and the evaporation heat of LTE 
is supplied by the external ambient air-source heat. The liquid refrigerant evaporates in the LTE and then the gaseous refrigerant flows to the low-temperature reactor (LTR) in LTDU to react with the salt.

The chemical synthesis heat released by the LTR in LTDU at a heat output temperature of $25^{\circ} \mathrm{C}$ is used to supply the evaporation heat of liquid ammonia in the high-temperature evaporator (HTE) in order to increase the working pressure in HTDU. Considering the heat transfer temperature difference $\left(\Delta T^{\prime}=10^{\circ} \mathrm{C}\right)$ between the LTR and the THE, the inlet temperature of heat transfer fluid of THE is kept at $15^{\circ} \mathrm{C}$, and it is observed that the temperature of high-temperature reactor (HTR) in the HTDU quickly increases to $70^{\circ} \mathrm{C}$, which means that the HTDU can produce thermal energy at a heat output temperature of $70^{\circ} \mathrm{C}$ although the ambient temperature is as low as $-15^{\circ} \mathrm{C}$ in winter. It indicates that the temperature-lift heating supply mode of seasonal thermochemical sorption energy storage system has the capability of producing thermal energy with a desirable temperature even though the ambient temperature is extremely low, and thus it can broaden the operating temperature range to a large extent when compared with the conventional seasonal thermal energy storage and supply technology. In LTDU, the chemical synthesis heat released by the LTR is used to provide the sensible heat consumption of itself with the temperature increasing from $-15^{\circ} \mathrm{C}$ to $25^{\circ} \mathrm{C}$, sensible heat consumption of HTE with the temperature increasing from $-15^{\circ} \mathrm{C}$ to $15^{\circ} \mathrm{C}$ and the evaporation heat consumption of liquid refrigerant in the HTE. In HTDU, part of the chemical synthesis heat released by the HTR is consumed by itself with temperature increasing from $-15^{\circ} \mathrm{C}$ to the heat output temperature, and the rest is used to provide the useful thermal energy for end user at a relatively high temperature. Experimental results shows that the thermal storage density and system COP are $305 \mathrm{~kJ} / \mathrm{kg}$ and 0.17 respectively at the ambient temperature of $-15^{\circ} \mathrm{C}$ and heat output 
temperature of $55^{\circ} \mathrm{C}$.

\subsubsection{Further theoretical analysis of temperature-lift heating supply mode of seasonal thermochemical sorption energy storage system}

The energy and temperature matches between the LTR in LTDU and the HTE in HTDU have strong influences on the performance of temperature-lift heating supply mode in dual-mode seasonal thermochemical sorption energy storage system. It has a strict requirement on the values of mass ratio, global conversion and temperature difference between the $T_{\mathrm{a}}$ and $T_{\text {out. In detail, Equation (14) and (15) gives the necessary }}$ conditions in order to make the temperature-lift heating supply mode of the proposed seasonal thermochemical sorption thermal energy storage system practicable.

$$
\begin{gathered}
Q_{\mathrm{r}, \mathrm{LTR}} \geq Q_{\mathrm{s}, \mathrm{LTR}}+Q_{\mathrm{s}, \mathrm{HTE}}+Q_{1, \mathrm{HTE}} \\
Q_{\mathrm{r}, \mathrm{HTR}}>Q_{\mathrm{s}, \mathrm{HTR}}
\end{gathered}
$$

where $Q_{\mathrm{r}, \mathrm{LTR}}$ is the chemical synthesis heat released by the LTR, $Q_{\mathrm{s}, \mathrm{LTR}}$ is the sensible heat consumption of LTR with temperature increasing from $T_{\mathrm{a}}$ to $T_{\mathrm{out}}, Q_{\mathrm{s}, \mathrm{HTE}}$ is the sensible heat consumption of the HTE with temperature increasing from $T_{\mathrm{a}}$ to $T_{\mathrm{H}-\mathrm{ev}}$ ( $T_{\mathrm{H} \text {-ev }}=T_{\left.\text {out } 1-\Delta T^{\prime}\right),} Q_{1, \mathrm{HTE}}$ is the latent heat consumption due to the evaporation of liquid ammonia in the HTE, $Q_{\mathrm{r}, \mathrm{HTR}}$ is the chemical synthesis heat produced by the HTR, and $Q_{\mathrm{s}, \mathrm{HTR}}$ is the sensible heat consumption of HTR with temperature increasing form $T_{\mathrm{a}}$ to $T_{\text {out2. }}$ When the sensible heat consumed by the composite sorbent and liquid ammonia are ignored, they can be calculated using the equation (16)-(20):

$$
\begin{gathered}
Q_{\mathrm{r}, \mathrm{LTR}}=Q_{\mathrm{r}, \mathrm{HTR}}=X M_{\text {salt }} \Delta H_{\mathrm{r}} \\
Q_{1, \mathrm{HTE}}=M_{\mathrm{NH}_{3}} \Delta H \\
Q_{\mathrm{s}, \mathrm{LTR}}=C_{\text {metal }} M_{\text {re-metal }}\left(T_{\text {out }}-T_{\mathrm{a}}\right)
\end{gathered}
$$




$$
\begin{gathered}
Q_{\mathrm{s}, \mathrm{HTE}}=C_{\text {metal }} M_{\text {ev-metal }}\left(T_{\mathrm{H}-\mathrm{ev}}-T_{\mathrm{a}}\right) \\
Q_{\mathrm{s}, \mathrm{HTR}}=C_{\text {metal }} M_{\text {re-metal }}\left(T_{\text {out2}}-T_{\mathrm{a}}\right)
\end{gathered}
$$

In order to investigate the relationship among the $R, X$ and temperature difference, some conditions are assumed that the metal mass of reactor and evaporator in the LTDU and HTDU are the same, the quantity of ammonia in the evaporator is equal to the total sorption quantity of sorbent, and the values of $\Delta T^{\prime}, T_{\mathrm{H}-\mathrm{ev}}$, and $T_{\mathrm{out} 2}$ are equal to $8^{\circ} \mathrm{C}, 0$ ${ }^{\circ} \mathrm{C}$, and $55^{\circ} \mathrm{C}$, respectively. Table 2 shows the value or relationship of related parameters. So the equation (21) and (22) can be obtained from the equation (14)-(20).

$$
\begin{aligned}
& R \leq 1867 X /\left(8-2 T_{\mathrm{a}}\right) \\
& R<3881 X /\left(55-T_{\mathrm{a}}\right)
\end{aligned}
$$

Fig. 11 shows that the maximum value of $R$ varies with the global conversion $X$ at different ambient temperatures based on the equation (21) and (22). When the ambient temperatures are at $-5^{\circ} \mathrm{C}$ and $-10^{\circ} \mathrm{C}$, the equation (22) determines the maximum value of $R$. Otherwise, when the ambient temperature is below $-10^{\circ} \mathrm{C}$, the equation (21) determines the maximum value of $R$. The maximum value of $R$ could act as a guide parameter when designing the temperature-lift heating supply mode of seasonal thermochemical sorption energy storage system. The global conversion can be improved by prolonging the charging and discharging time and enhancing the capacity of heat and mass transfer of composite sorbent.

The parameters of $R$ and $X$ determine the feasibility of the temperature-lift heating supply mode in dual-mode seasonal thermochemical sorption energy storage system. The proposed heat recovery between the LTR and the HTE is only possible if the total amount of heat released and heat output temperature of the LTR are equal or higher than the total amount of heat consumed and heat input temperature of the HTE. Low mass ratio $R$ and high global conversion $X$ would be desirable as the ambient 
temperature becomes low in winter during the discharging phase in order to assure the feasibility of the temperature-lift heating supply mode.

\subsection{Further discussion on the potential application and existing problem}

Long-term and compact storage of solar energy is crucial for the eventual transition to a $100 \%$ renewable energy economy, and thermochemical energy storage system provides a promising solution to achieve long-term energy storage system [29]. The practical applications of different long-term/seasonal sorption heat storage systems have been widely discussed and analyzed [30, 31]. The most researches are focused on the system energy density, economic considerations, reactor design, and so on. It indicates that long-term/seasonal sorption heat storage technologies are becoming mature and entering the commercialization stage. However, the common thermochemical energy storage methods like thermo-chemical/physical sorption based on water and conventional single-stage thermochemical sorption based on ammonia exist some inherent drawbacks, for example, when the ambient temperature is lower than $0^{\circ} \mathrm{C}$, the water-based system will cannot work, and single-stage ammonia-based system cannot produce a relatively high heat output temperature due to the relatively low working pressure caused by the low ambient temperature. Thus, it is urgent to extend the working temperature range by developing advanced thermochemical sorption energy storage technology.

The proposed dual-mode thermochemical sorption energy storage system provides the possible method for broadening the application range of sorption energy storage to a large extent, and can be applied in the area where the ambient temperature in winter is even far lower than $0^{\circ} \mathrm{C}$. The dual-mode thermochemical sorption energy storage system cannot only be used for short-term energy storage similar to the conventional 
energy storage methods, but also for long-term seasonal energy storage because it has the distinct advantage of temperature-lift heating supply for energy upgrade when compared with conventional thermochemical sorption energy storage. In addition, it can also realize the flexible heat output temperature by matching the working temperature between the HTDU and LTDU to meet various heat demands such as space heating, domestic hot water for buildings, temperature-lift of low-grade waste heat, and so on. When considering the system commercialization, it is important to improve the system structure to minimize the system size and achieve high system storage density. The main hurdles are the high mass ratio of metallic part to the reactive salt and low global conversion of salt. They both cause the low energy density and system COP. Thus, it is desirable to lower the mass ratio and improve the global conversion as much as possible, which require the structure optimization of reactor and high heat and mass transfer performance of composite sorbent.

\section{Conclusions}

A dual-mode seasonal solar thermochemical sorption energy storage system using sorption working pair of expanded graphite/strontium chloride-ammonia was developed and experimentally investigated. The presented system has two discharging modes, including the direct heating supply and temperature-lift heating supply, to produce the thermal energy with expected heat output temperature for end user according to different ambient temperatures in winter. The main experimental results obtained are as follows:

(1) The advanced dual-mode seasonal solar thermochemical sorption energy storage is feasible and effective to produce useful thermal energy for end user after the long-term storage of solar thermal energy whether at high or low ambient temperatures in winter. 
(2) For direct heating supply mode, the effective thermal energy storage density and system COP are as high as $706 \mathrm{~kJ} / \mathrm{kg}$ and 0.41 respectively when the heat output temperature is $35^{\circ} \mathrm{C}$ at an ambient temperature of $15^{\circ} \mathrm{C}$ in winter. The effective thermal energy storage density decreases with increasing heat output temperature at a certain ambient temperature.

(3) For temperature-lift heating supply mode, the heat output temperature can be enhanced even if ambient temperature is very low in winter. The thermal energy storage density and system COP are $305 \mathrm{~kJ} / \mathrm{kg}$ and 0.17 respectively under the conditions of heat output temperature of $55^{\circ} \mathrm{C}$ and ambient temperature of $-15^{\circ} \mathrm{C}$ in winter.

(4) The low heat output temperature contributes to improving the specific heating power (SHP). The peak SHP is about $643 \mathrm{~W} / \mathrm{kg}$ at a heat output temperature of $35^{\circ} \mathrm{C}$ when the ambient temperature is $5^{\circ} \mathrm{C}$.

(5) Lowering the mass ratio of metallic part to reactive salt in the reactor and increasing the global conversion of salt can achieve the better system performance by optimizing the structure of heat exchanger in reactor and improving the high heat and mass transfer performance of composite sorbent.

\section{Acknowledgments}

This work was supported by the National Natural Science Funds for Excellent Young Scholar of China under the contract No.51522604 and the International Exchange Program of the Natural Science Foundation of China under the contract No.5151101412.

\section{References}

[1] Gur I, Sawyer K, Prasher R. Searching for a Better Thermal Battery. Science 2012; 335: 1454-1455.

[2] Li G, Qian SX, Lee H, Hwang Y, Radermacher R. Experimental investigation of energy and exergy performance 
of short term adsorption heat storage for residential application. Energy 2014; 65:675-691.

[3] Dincer I, Rosen MA. Thermal energy storage: systems and applications. 2nd ed. Chichester, United Kingdom: John Wiley \& Sons Ltd; 2011.

[4] Xu J, Wang RZ, Li Y. A review of available technologies for seasonal thermal energy storage. Sol Energy 2014; 103: $610-38$.

[5] Bauer D, Marx R, Nußbicker-Lux J, Ochs F, Heidemann W, Müller-Steinhagen H. German central solar heating plants with seasonal heat storage. Sol Energy 2010; 84(4): 612-23.

[6] Zhao DL, Li Y, Dai YJ, Wang RZ. Optimal study of a solar air heating system with pebble bed energy storage. Energ Convers Manage 2011; 52: 2392-2400.

[7] Reuss M, Beck M, Muller JP. Design of a seasonal thermal energy storage in the ground. Sol Energy 1997; 59 : 247-257.

[8] Li TX, Lee JH, Wang RZ, Kang YT, Enhancement of heat transfer for thermal energy storage application using stearic acid nanocomposite with multi-walled carbon nanotubes. Energy 2013; 55:752-761.

[9] Zalba B, Marın JM, Cabeza LF, Mehling H. Review on thermal energy storage with phase change: materials, heat transfer analysis and applications. Appl Therm Eng 2003; 23: 251-283.

[10] Dannemand M, Schultz JRM, Johansen JB, Furbo S. Long term thermal energy storage with stable supercooled sodium acetate trihydrate. Appl Therm Eng 2015; 91: 671-8.

[11] Li TX, Wang RZ, Yan T, Ishugah TF. Integrated energy storage and energy upgrade, combined cooling and heating supply, and waste heat recovery with solid-gas thermochemical sorption heat transformer. Int J Heat Mass Tran 2014; 76: 237-246.

[12] Li TX, Wang RZ, Kiplagat JK. A target-oriented solid-gas thermochemical sorption heat transformer for integrated energy storage and energy upgrade. AIChE Journal 2013; 59: 1334-1347.

[13] N'Tsoukpoe KE, Liu H, Pierres NL, Luo LG. A review on long-term sorption solar energy storage. Renew Sust Energy Rev 2009; 13: 2385-96.

[14] Yu N, Wang RZ, Wang LW. Sorption thermal storage for solar energy. Prog Energy Combust Sci 2013; 39(5):489-514.

[15] Jaenchen J, Ackermann D, Stach H, Broesicke W. Studies of the water adsorption on zeolites and modified mesoporous materials for seasonal storage of solar heat. Sol Energy 2004; 76: 334-9.

[16] Aristov YI. Challenging offers of material science for adsorption heat transformation: a review. Appl Therm Eng 2013; 50: 1610-8.

[17] Cot-Gores J, Castell A, Cabeza LF. Thermochemical energy storage and conversion: a-state-of-the-art review of the experimental research under practical conditions. Renew Sust Energy Rev 2012; 16: 5207-24.

[18] Hongois S, Kuznik F, Stevens P. Development and characterization of a new $\mathrm{MgSO}_{4}$-zeolite composite for long-term thermal energy storage. Sol Energ Mat Sol C 2011; 95: 1831-7. 
[19] Mauran S, Lahmidi H, Goetz V. Solar heating and cooling by a thermochemical process. First experiments of a prototype storing $60 \mathrm{kWh}$ by a solid/gas reaction. Sol Energy 2008; 82: 623-36.

[20] Michel B, Mazet N, Mauran S, Stitou D, Xu J. Thermochemical process for seasonal storage of solar energy: characterization and modeling of a high density reactive bed. Energy 2012; 47(1):553-63.

[21] Pons M, Meunier F, Cacciola G, Critoph RE, Groll M, Puigjaner L, Spinner B, Ziegler F. Thermodynamic based comparison of sorption systems for cooling and heat pumping. Int J Refrig 1999; 22: 5-17.

[22] Li TX, Wang RZ, Yan T. Solid-gas thermochemical sorption thermal battery for solar cooling and heating energy storage and heat transformer. Energy 2015; 84: 745-758.

[23] Li TX, Xu JX, Yan T, Wang RZ. Development of sorption thermal battery for low-grade waste heat recovery and combined cold and heat energy storage. Energy 2016; 107: 347-359.

[24] Li TX, Wu S, Yan T, Xu JX, Wang RZ. A novel solid-gas thermochemical multilevel sorption thermal battery for cascaded solar thermal energy storage. Appl Energ 2016; 161: 1-10.

[25] Li TX, Wang RZ, Kiplagat JK, Kang YT. Performance analysis of an integrated energy storage and energy upgrade thermochemical solid-gas sorption system for seasonal storage of solar thermal energy. Energy 2013; 50: 454-67.

[26] Neveu P, Castaing J. Solid-gas chemical heat pumps: Field of application and performance of the internal heat of reaction recovery process. Heat Recovery System \& CHP 1993; 13(3): 233-251.

[27] Oliveira RG, Wang RZ. A consolidated calcium chloride-expanded graphite compound for use in adsorption refrigeration systems. Carbon 2007; 45(2): 390-396.

[28] Goetz V, Llobet J, Testing and modelling of a temperature front solid-gas reactor applied to thermochemical transformer. Appl Therm Eng 2000; 20(2): 155-177.

[29] Ard-Jan de Jong, Laurens van Vliet, Christophe Hoegaerts, Mark Roelands, Ruud Cuypers. Thermochemical heat storage - from reaction storage density to system storage density. Energy Procedia 2016; 91: 128-137.

[30] Scapino L, Zondag HA, Van Bael J, Diriken J, Rindt CCM. Energy density and storage capacity cost comparison of conceptual solid and liquid sorption seasonal heat storage systems for low-temperature space heating. Renew Sust Energy Rev 2017; 76: 1314-1331.

[31] Scapino L, Zondag HA, Van Bael J, Diriken J, Rindt CCM. Sorption heat storage for long-term low-temperature applications: A review on the advancements at material and prototype scale. Appl Energ 2017; 190: 920-48. 


\section{Figure Captions}

Fig. 1 Schematic diagram of the temperature-lift heating supply mode of dualmode solid-gas thermochemical sorption energy storage system for seasonal solar thermal energy storage

Fig. 2 Photograph of seasonal thermochemical sorption energy storage system

Fig. 3 Working temperature range of dual-mode thermochemical sorption energy storage system during the discharging phase

Fig. 4 Temperature evolution curves with the heat source temperature of $94^{\circ} \mathrm{C}$ in summer and ambient temperature of $10^{\circ} \mathrm{C}$ in winter

Fig. 5 Temperature evolution curves with the heat output temperature of $45^{\circ} \mathrm{C}$ and ambient temperature of $10^{\circ} \mathrm{C}$ during the discharging phase in winter

Fig. 6 Variation of sensible heat consumption of reactor with its temperature difference between the initial temperature and heat output temperature

Fig. 7 Thermal storage density and system COP of seasonal solar thermal energy storage

Fig. 8 Variation of specific heating power (SHP) with time at ambient temperature of $5^{\circ} \mathrm{C}$

Fig. 9 Variation of COP with mass ratio $R$ at different global conversions $X$ and temperature differences

Fig. 10 The discharging process of temperature-lift heating supply mode of seasonal thermochemical sorption energy storage system

Fig. 11 The variation of maximum mass ratio with the global conversion at different ambient temperatures 


\section{List of figures}

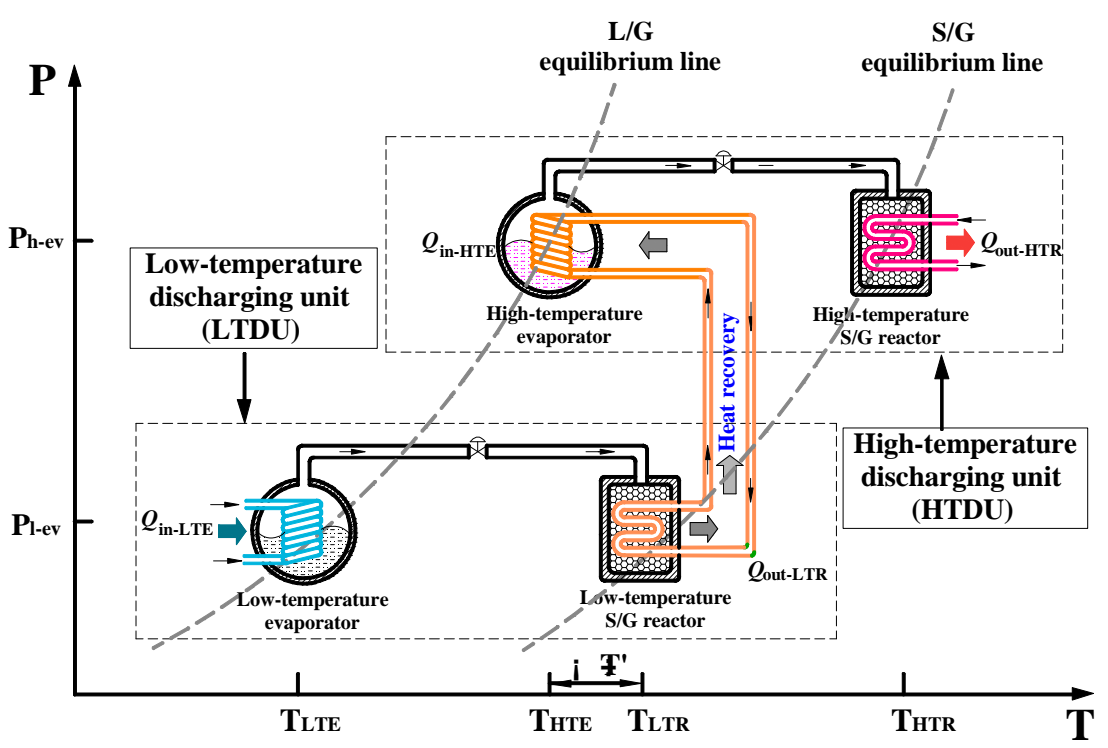

(a) Internal heat recovery process between LTR and HTE

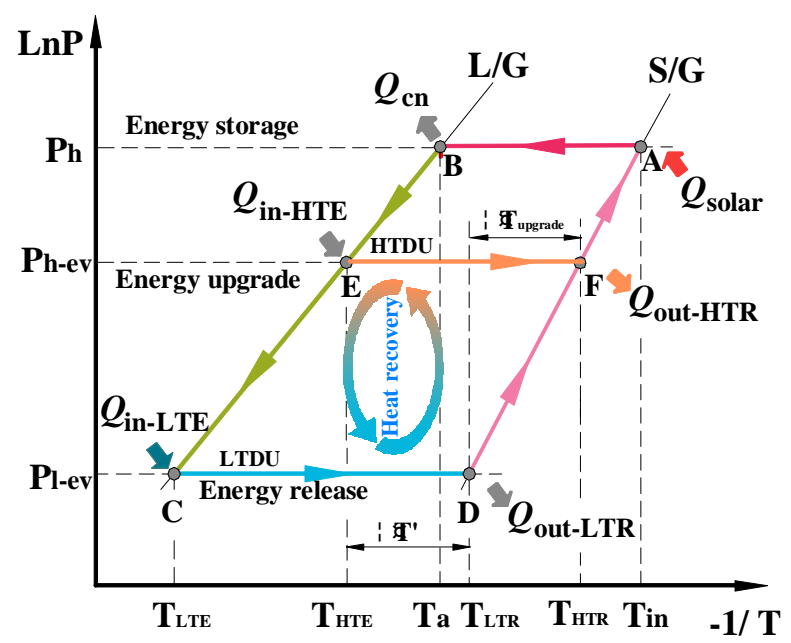

Energy storage process: A-B; Energy release process of LTDU: C-D

Energy upgrade process of HTDU: E-F

(b) Clapeyron diagram

Fig.1. Schematic diagram of the temperature-lift heating supply mode of dual-mode solid-gas thermochemical sorption energy storage system for seasonal solar thermal energy storage 


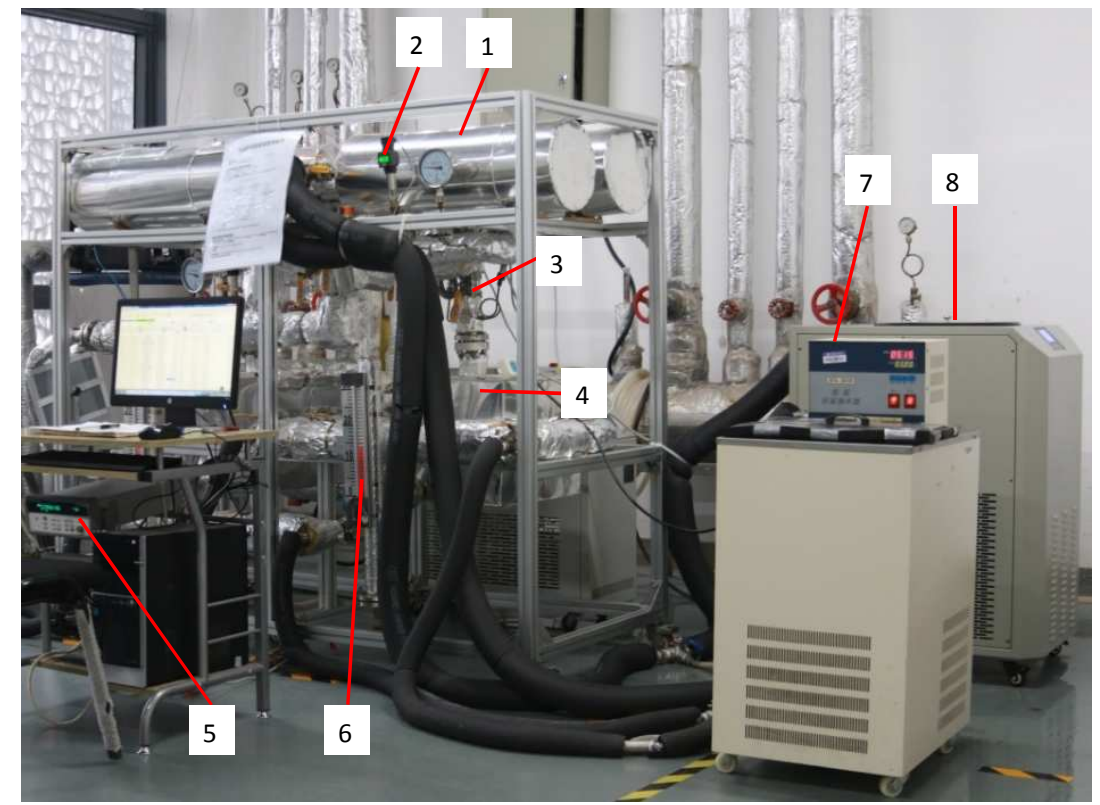

(1) Reactor; (2) Pressure sensor; (3) Ammonia valve; (4) Evaporator/condenser;

(5) Data logger; (6) float level meter; (7) Low-temperature thermostatic bath; (8) High-temperature thermostatic bath

Fig. 2. Photograph of seasonal thermochemical sorption energy storage system 


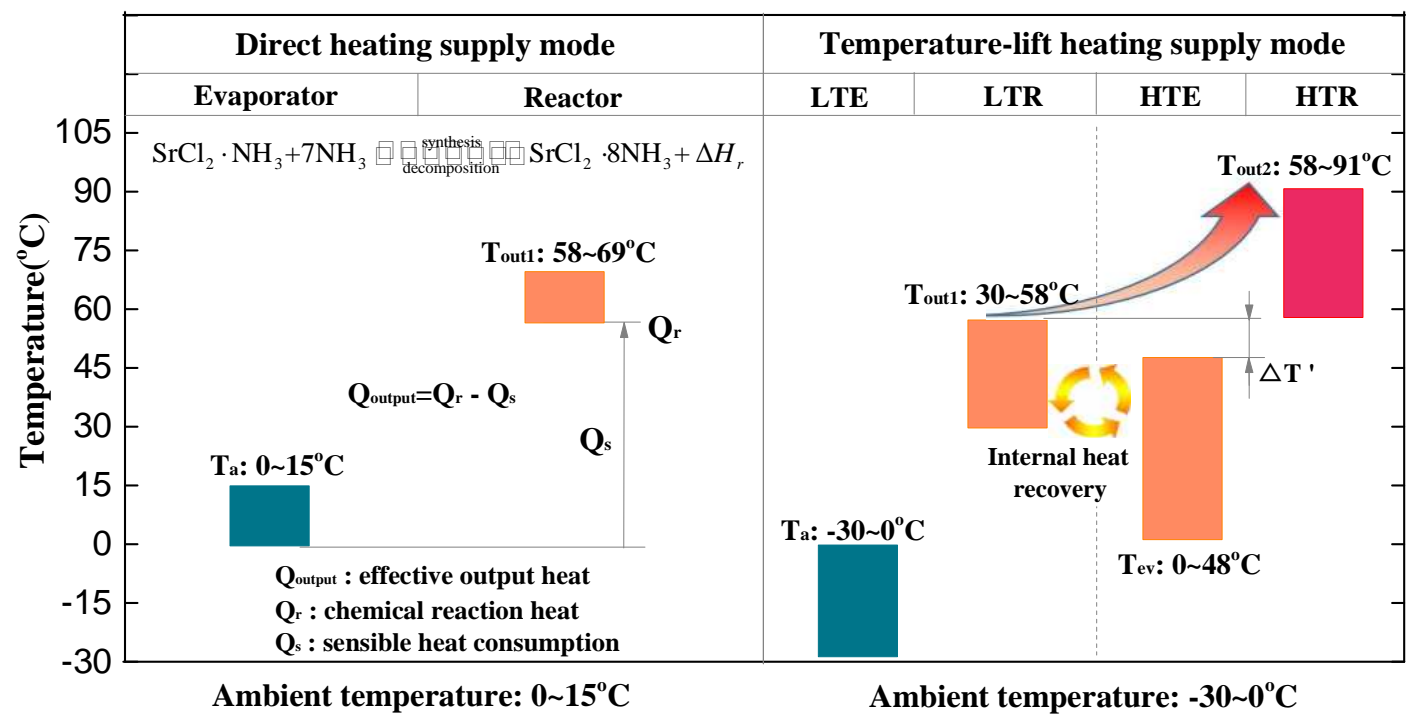

Fig.3. Working temperature range of dual-mode thermochemical sorption energy storage system during the discharging phase 


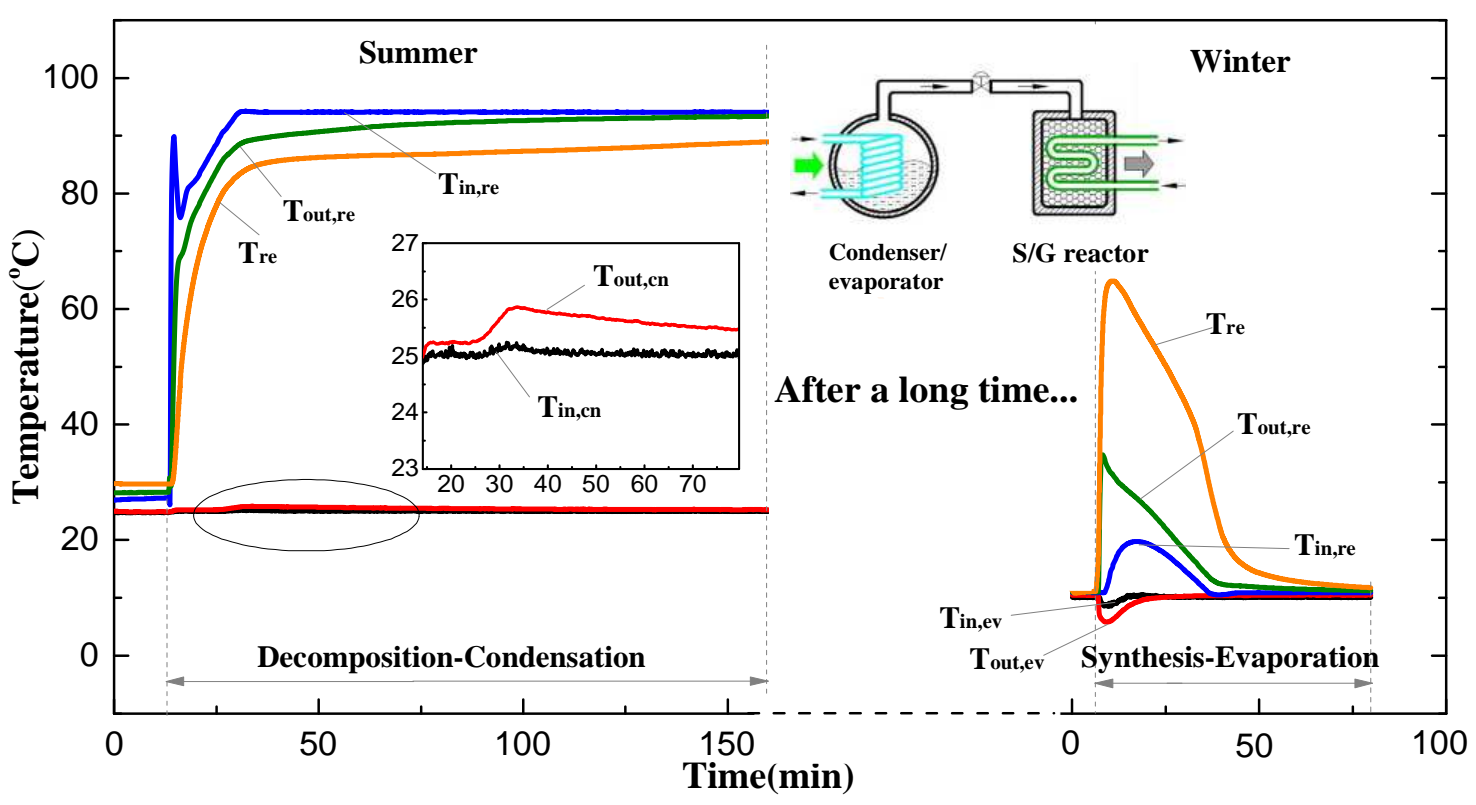

Fig.4. Temperature evolution curves with the heat source temperature of $94^{\circ} \mathrm{C}$ in summer and ambient temperature of $10^{\circ} \mathrm{C}$ in winter 


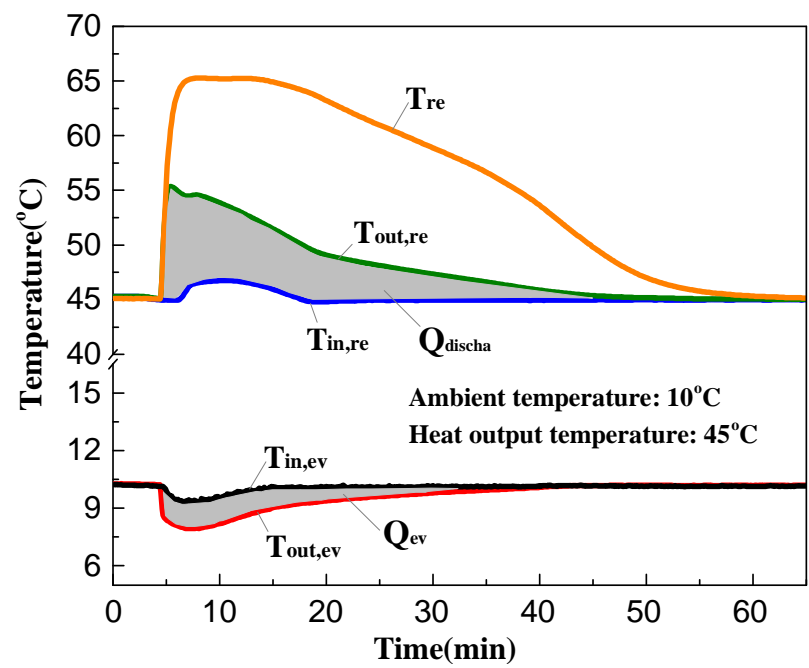

Fig.5. Temperature evolution curves with the heat output temperature of $45^{\circ} \mathrm{C}$ and ambient temperature of $10^{\circ} \mathrm{C}$ during the discharging phase in winter 


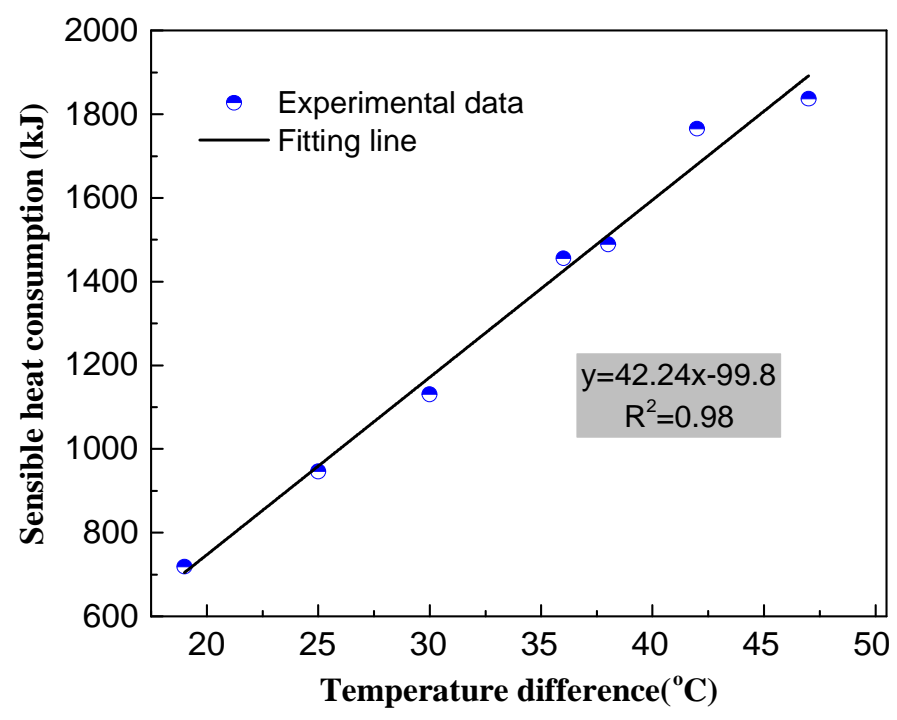

Fig.6. Variation of sensible heat consumption of reactor with its temperature difference between the initial temperature and heat output temperature 


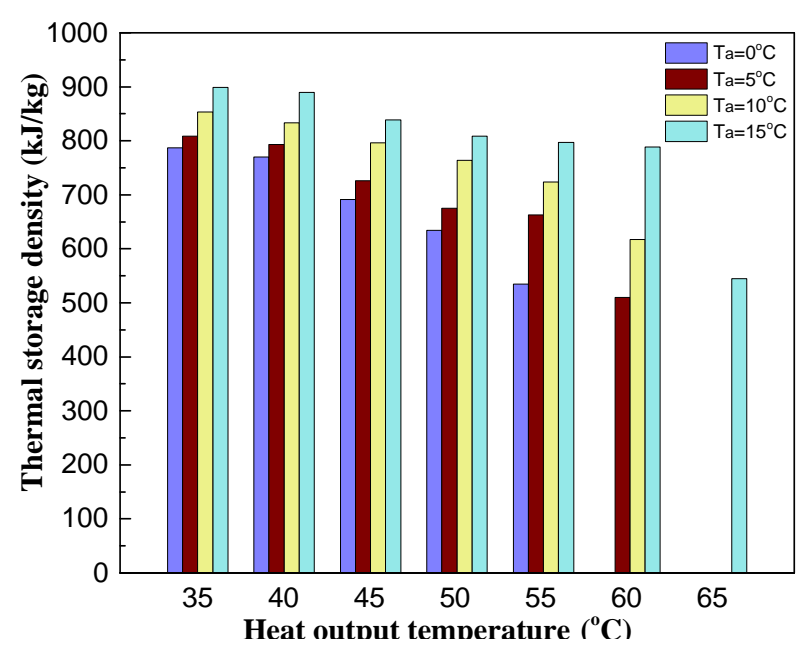

(a) Mass thermal storage density

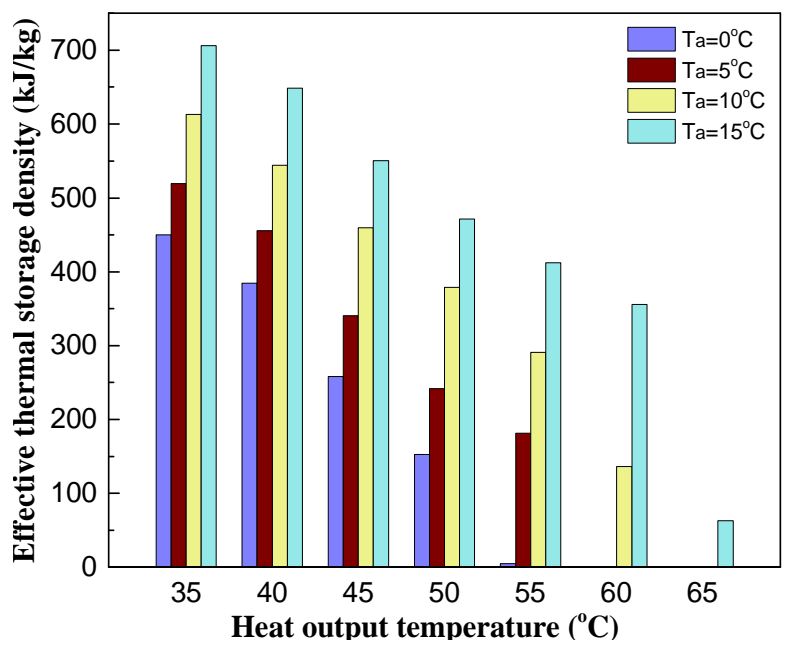

(b) Effective mass thermal storage density

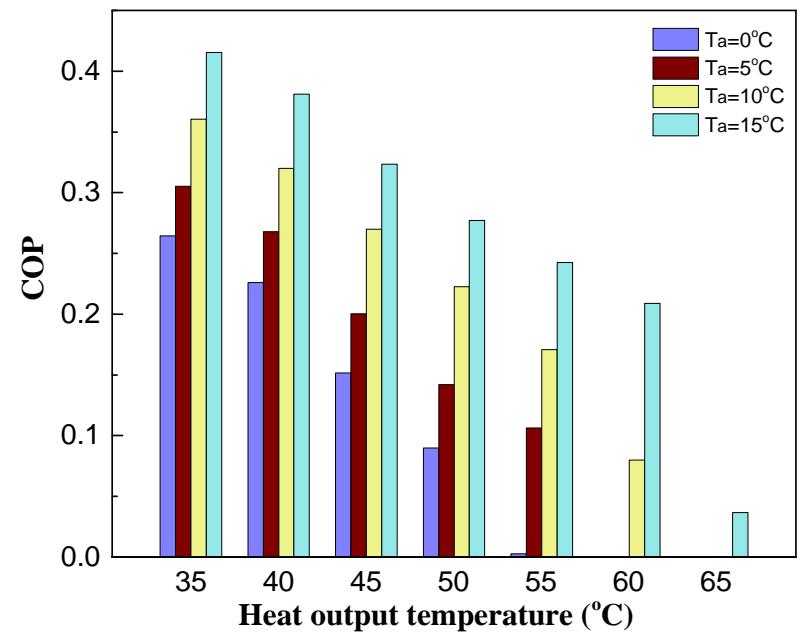

(c) COP based on effective heat output

Fig.7. Thermal storage density and system COP of seasonal solar thermal energy storage 


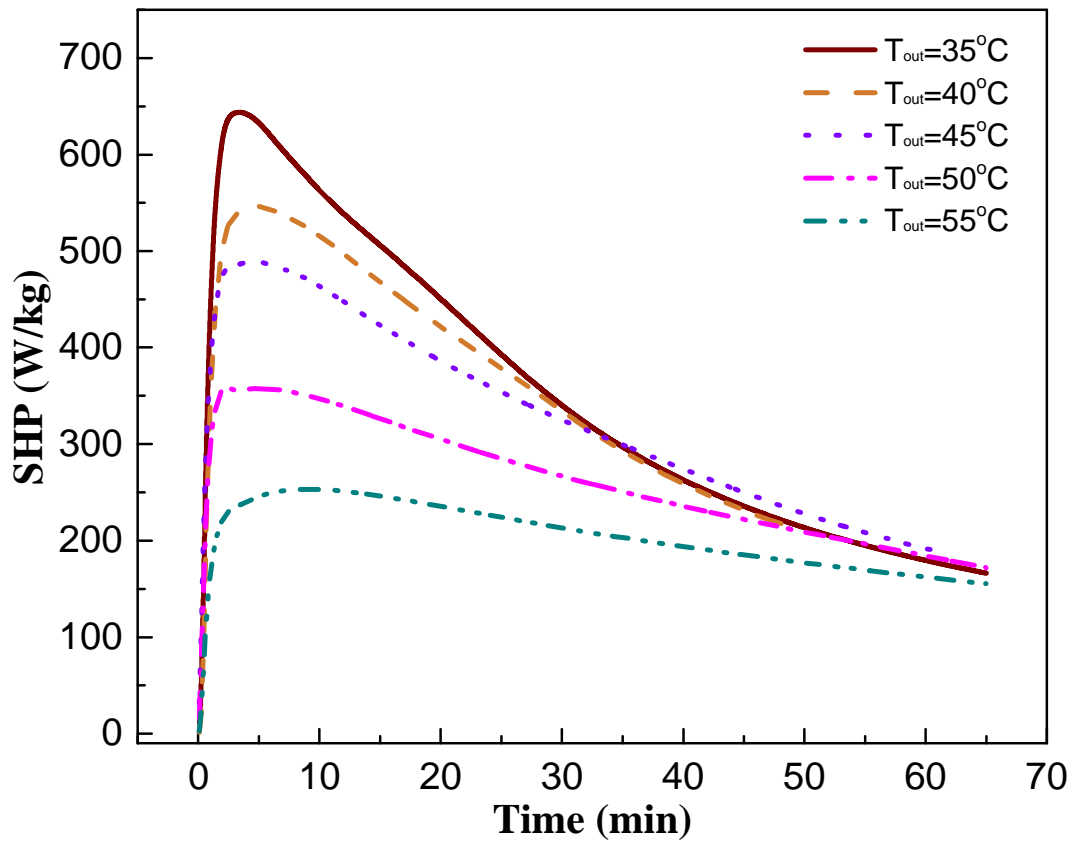

Fig.8. Variation of specific heating power (SHP) with time at ambient temperature of $5^{\circ} \mathrm{C}$ 


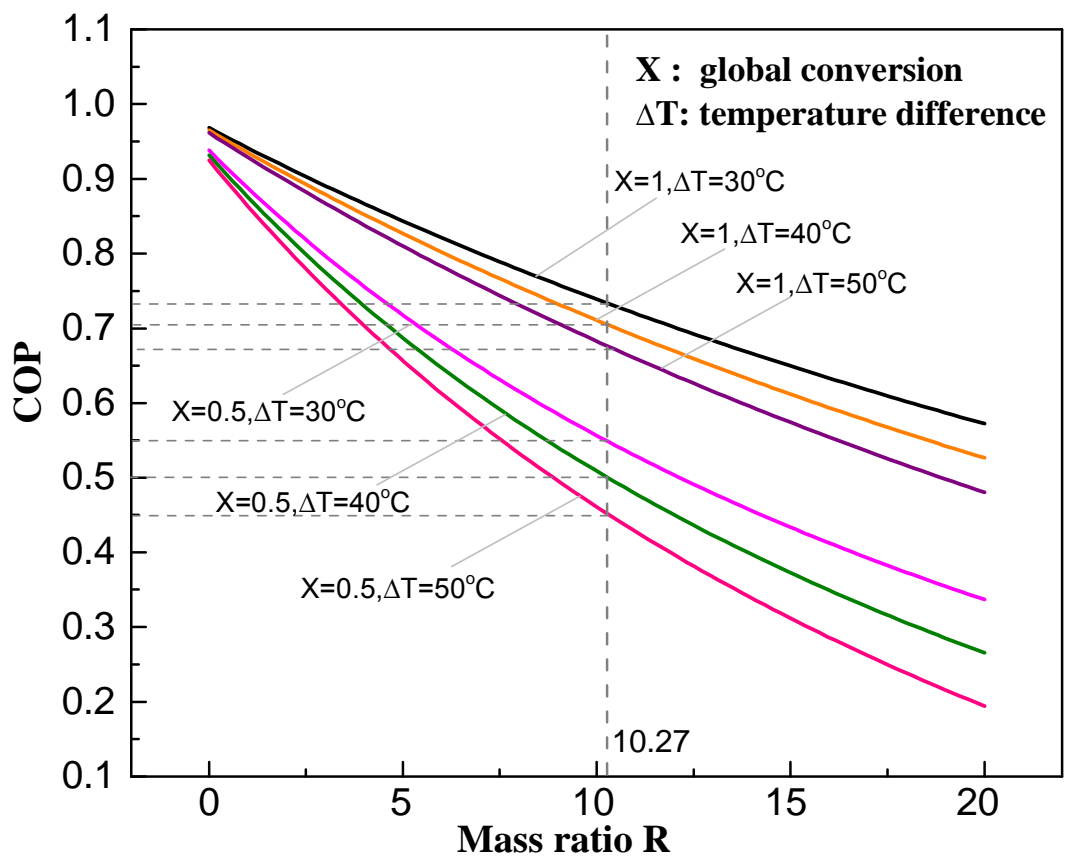

Fig.9. Variation of COP with mass ratio $R$ at different global conversions $X$ and temperature differences 


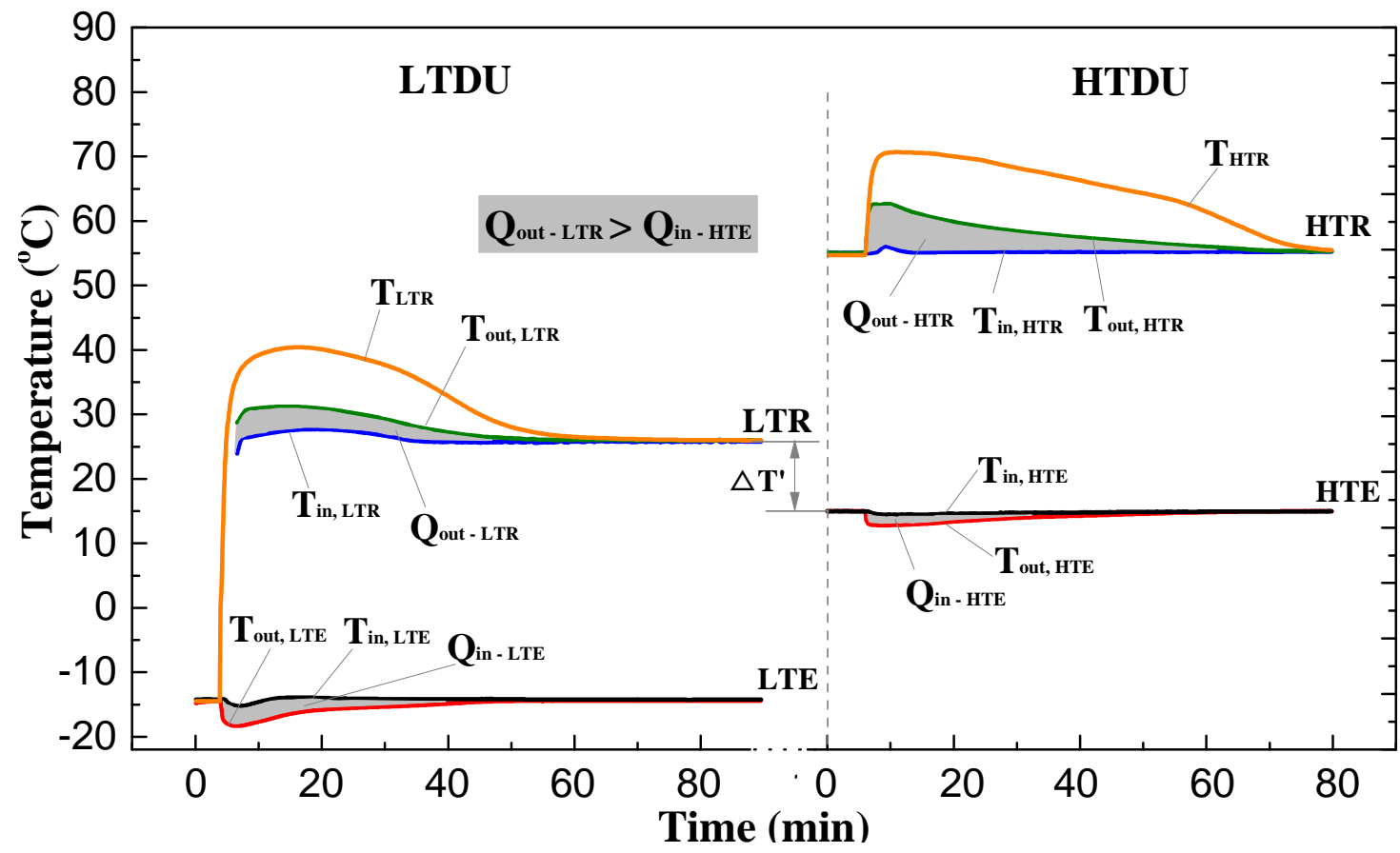

Fig.10. The discharging process of temperature-lift heating supply mode of seasonal thermochemical sorption energy storage system 


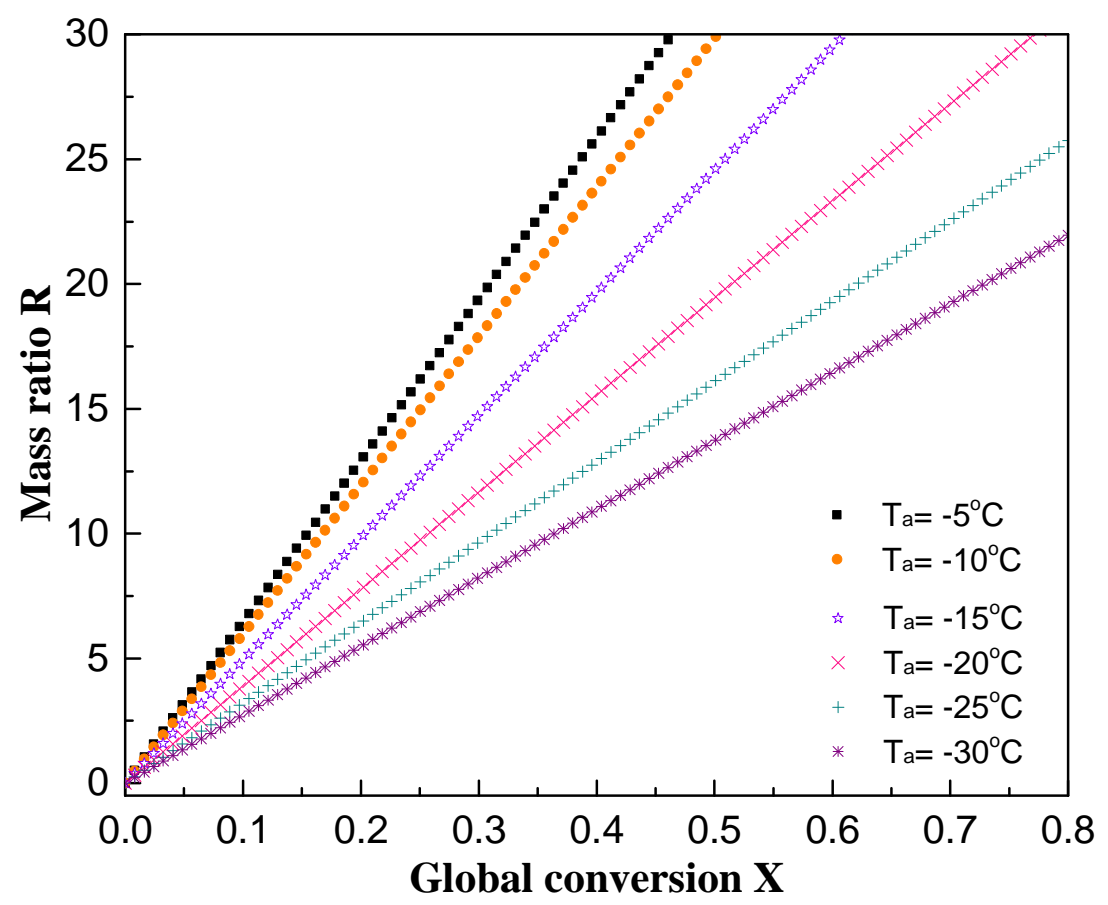

Fig.11. The variation of maximum mass ratio with the global conversion at different ambient temperatures. 


\section{List of Tables}

Table 1 Heat storage densities and operating conditions of several candidate sorption working pairs at $\mathrm{T}_{\mathrm{ev}}=0^{\circ} \mathrm{C}$ and $\mathrm{T}_{\mathrm{cn}}=25^{\circ} \mathrm{C}$ [26]

\begin{tabular}{cccc}
\hline Reaction & $\mathrm{T}_{\mathrm{de}}\left({ }^{\circ} \mathrm{C}\right)$ & $\mathrm{T}_{\mathrm{ad}}\left({ }^{\circ} \mathrm{C}\right)$ & $\mathrm{Q} / \mathrm{m}(\mathrm{kJ} / \mathrm{kg}$ salt $)$ \\
\hline $\mathrm{SrBr}_{2} \cdot 2 \mathrm{NH}_{3}+6 \mathrm{NH}_{3} \leftrightarrow \mathrm{SrBr}_{2} \cdot 8 \mathrm{NH}_{3}$ & 126 & 102 & 1048 \\
$\mathrm{CaCl}_{2} \cdot 2 \mathrm{NH}_{3}+2 \mathrm{NH}_{3} \leftrightarrow \mathrm{CaCl}_{2} \cdot 4 \mathrm{NH}_{3}$ & 96 & 74 & 762 \\
$\mathrm{SrCl}_{2} \cdot \mathrm{NH}_{3}+7 \mathrm{NH}_{3} \leftrightarrow \mathrm{SrCl}_{2} \cdot 8 \mathrm{NH}_{3}$ & 90 & 70 & 1824 \\
$\mathrm{CaCl}_{2} \cdot 4 \mathrm{NH}_{3}+4 \mathrm{NH}_{3} \leftrightarrow \mathrm{CaCl}_{2} \cdot 8 \mathrm{NH}_{3}$ & 83 & 62 & 1477 \\
\hline
\end{tabular}


Table 2 The value or relationship of working parameters

\begin{tabular}{|c|c|c|c|c|c|c|c|c|c|}
\hline \multirow{2}{*}{$\begin{array}{l}\text { Specific thermal capacity } \\
\qquad(\mathrm{kJ} / \mathrm{kgK}) \\
C_{\text {metal }}\end{array}$} & \multicolumn{3}{|c|}{$\begin{array}{c}\text { Temperature } \\
\left({ }^{\circ} \mathrm{C}\right)\end{array}$} & \multicolumn{4}{|c|}{$\begin{array}{l}\text { Mass } \\
(\mathrm{kg})\end{array}$} & \multicolumn{2}{|c|}{$\begin{array}{c}\text { Enthalpy } \\
(\mathrm{kJ} / \mathrm{kg})\end{array}$} \\
\hline & $T_{\text {out } 1}$ & $T_{\text {out } 2}$ & $T_{\mathrm{H}-\mathrm{ev}}$ & $M_{\text {salt }}$ & $M_{\mathrm{NH} 3}$ & $M_{\text {re-metal }}$ & $M_{\text {ev-metal }}$ & $\Delta H$ & $\Delta H_{\mathrm{r}}$ \\
\hline 0.47 & 8 & 55 & 0 & $M_{\mathrm{NH}}$ & $\begin{array}{r}=0.75 X N \\
R=\end{array}$ & $\begin{array}{l}\text { salt } ; M_{\text {re-meta }} \\
M_{\text {metal }} / M_{\text {salt }}\end{array}$ & $M_{\mathrm{ev}-\mathrm{metal}}$ & 1262 & 1824 [28] \\
\hline
\end{tabular}

